\title{
THE
}

\section{Identification of Borrelia burgdorferi ospC genotypes in canine tissue following tick infestation: Implications for Lyme disease vaccine and diagnostic assay design}

\author{
D. V.L. Rhodes \\ C. G. Earnhart
}

Thomas N. Mather

University of Rhode Island, tmather@uri.edu

P. F.M. Meeus

R. T. Marconi

Follow this and additional works at: https://digitalcommons.uri.edu/pls_facpubs

This is a pre-publication author manuscript of the final, published article.

Creative Commons License

(c) (i) $\ominus$

This work is licensed under a Creative Commons Attribution-Noncommercial-No Derivative Works 4.0 License.

\section{Citation/Publisher Attribution}

Rhodes, D. V.L., Earnhart, C. G., Mather, T. N., Meeus, P. F.M., \& Marconi, R. T. (2013). Identification of Borrelia burgdorferi ospC genotypes in canine tissue following tick infestation: Implications for Lyme disease vaccine and diagnostic assay design. The Veterinary Journal, 198(2), 412-418. doi: 10.1016/ j.tvjl.2013.07.019

Available at:

This Article is brought to you for free and open access by the Plant Sciences and Entomology at DigitalCommons@URI. It has been accepted for inclusion in Plant Sciences and Entomology Faculty Publications by an authorized administrator of DigitalCommons@URI. For more information, please contact digitalcommonsgroup@uri.edu. 
Vet J. 2013 November ; 198(2): . doi:10.1016/j.tvj1.2013.07.019.

\title{
Identification of Borrelia burgdorferi ospC genotypes in canine tissue following tick infestation: Implications for Lyme disease vaccine and diagnostic assay design
}

\author{
D.V.L. Rhodes ${ }^{a}$, C.G. Earnhart ${ }^{\mathrm{a}}$, T.N. Mather ${ }^{\mathrm{c}}$, P.F.M Meeus ${ }^{\mathrm{d}}$, and R.T. Marconi ${ }^{\mathrm{a}, \mathrm{b},{ }^{*}}$ \\ aDepartment of Microbiology and Immunology, Virginia Commonwealth University, Richmond, VA \\ 23298-0678, USA \\ ${ }^{b}$ Center for the Study of Biological Complexity, Virginia Commonwealth University, Richmond, VA \\ 23298-0678, USA \\ 'University of Rhode Island, Center for Vector-Borne Disease, Kingston, RI 02881, USA \\ dVeterinary Medicine Research and Development, Zoetis, MI 49007, USA
}

\section{Abstract}

In endemic regions, Lyme disease is a potential health threat to dogs. Canine Lyme disease manifests with arthritis-induced lameness, anorexia, fever, lethargy, lymphadenopathy and, in some cases, fatal glomerulonephritis. A recent study revealed that the regional mean for the percentage of seropositive dogs in the Northeast of the USA is $11.6 \%$. The outer surface protein C (OspC) of Lyme disease spirochetes is an important virulence factor required for the establishment of infection in mammals. It is a leading candidate in human and canine Lyme disease vaccine development efforts. Over 30 distinct $o s p C$ phyletic types have been defined. It has been hypothesized that $\operatorname{sp} C$ genotype may influence mammalian host range. In this study, Ixodes scapularis ticks collected from the field in Rhode Island were assessed for infection with $B$. burgdorferi. Ticks were fed on purpose bred beagles to repletion and infection of the dogs was assessed through serology and PCR. Tissue biopsies $(n=2)$ were collected from each dog 49 days post-tick infestation (dpi) and the $\operatorname{ssp} C$ genotype of the infecting strains determined by direct PCR of DNA extracted from tissue or by PCR after cultivation of spirochetes from biopsy samples. The dominant $\operatorname{ss} \mathrm{C}$ types associated with B. burgdorferi canine infections differed from those associated with human infection, indicating a relationship between $\operatorname{sp} C$ sequence and preferred host range. Knowledge of the most common $\operatorname{sp} C$ genotypes associated specifically with infection of dogs will facilitate the rational design of OspC-based canine Lyme disease vaccines and diagnostic assays.

\section{Keywords}

Lyme disease; Borrelia burgdorferi; Ticks; Canine; OspC; Vaccine

\footnotetext{
(C) 2013 Elsevier Ltd. All rights reserved.

*Corresponding author. Tel.: +1 804 8283779. rmarconi@vcu.edu(R.T. Marconi).
}

Publisher's Disclaimer: This is a PDF file of an unedited manuscript that has been accepted for publication. As a service to our customers we are providing this early version of the manuscript. The manuscript will undergo copyediting, typesetting, and review of the resulting proof before it is published in its final citable form. Please note that during the production process errors may be discovered which could affect the content, and all legal disclaimers that apply to the journal pertain.

Conflict of interest statement

Intellectual property developed by Drs Marconi and Earnhart as an extension of this study is owned and is being patented by Virginia Commonwealth University. Zoetis has licensed this intellectual property and has contributed in part to funding this research. 


\section{Introduction}

Borrelia burgdorferi, the primary causative agent of Lyme disease in North America, is transmitted to mammals through the bite of Ixodes spp. ticks (Burgdorfer et al., 1982; Benach et al., 1983). In 2009, nearly 38,000 cases of confirmed and probable human Lyme disease were reported in the United States ${ }^{1}$. In Europe, additional Borrelia spp., including $B$. garinii, and B. afzelii, have been identified and demonstrated to cause Lyme disease (Baranton et al., 1992; Marconi and Garon, 1992). While the incidence of Lyme disease is thought to be higher in Europe, estimates of case numbers are not known accurately due to a lack of uniform reporting criteria. Lyme disease is a potential health threat to dogs in both North America and Europe (Krupka and Straubinger, 2010; Little et al., 2010). In dogs, Lyme disease may manifest with arthritis-induced lameness, anorexia, fever, lethargy, lymphadenopathy and, in some cases, fatal glomerulonephritis (Little et al., 2010). A recent study revealed that the percentage of seropositive dogs in the Northeast states of the USA ranges from $7.1 \%$ in New York to $19.8 \%$ in Massachusetts, with a regional mean of $11.6 \%$ (Bowman et al., 2009). In the Midwest of the USA, this value ranges from $<1 \%$ in several states to $10.2 \%$ in Wisconsin, with a regional mean of $4.0 \%$ (Bowman et al., 2009).

Strategies to prevent infection in dogs have focused on acaricides and vaccination. Acaricides are effective at decreasing tick burdens, but do not provide complete protection and, depending on delivery approach, may require frequent (monthly) applications. While several Lyme disease vaccines have been licensed for use in dogs, the broad protective efficacy and ability to induce long term protective immunity is low (Littman et al., 2006; Earnhart and Marconi, 2008; Marconi and Earnhart, 2010). In a recent study, a multi-strain B. burgdorferi bacterin vaccine provided protection against tick challenge for 1 year (LaFleur et al., 2010). However, Borrelia spp. based bacterin vaccines are expensive to produce and it is difficult to maintain consistent quality. There is a clear and pressing need for development of subunit vaccines for canine Lyme disease.

Outer surface protein C (OspC) is a $22 \mathrm{kDa}$ surface-exposed lipoprotein (Fuchs et al., 1992) encoded by a stable and universal $26 \mathrm{~kb}$ circular plasmid (Marconi et al., 1993a and b; Sadziene et al., 1993). OspC is an essential virulence factor that has been postulated to participate in interactions with tick or host-derived ligands at the tick-host interface that are required for the establishment of infection (Hovius et al., 2008; Earnhart et al., 2010; Onder et al., 2012). OspC elicits robust and protective antibody responses, making it an attractive candidate for vaccine development (reviewed in Earnhart and Marconi, 2008; Marconi and Earnhart, 2010).

A challenge encountered in efforts to develop OspC as a vaccine is its inherent genetic diversity (Theisen et al., 1993, 1995; Wilske et al., 1993, 1995; Lagal et al., 2006; Earnhart and Marconi, 2007c). Over 30 distinct ospC phyletic types have been identified (Seinost et al., 1999a; Wang et al., 1999; Brisson and Dykhuizen, 2004; Earnhart and Marconi, 2007c). Immune responses elicited by OspC protective epitopes are 'phyletic type' specific (Earnhart et al., 2005; Buckles et al., 2006; Earnhart and Marconi, 2007b). Hence, a broadly protective OspC based vaccine must include protective epitopes derived from $o s p C$ variants most commonly associated with mammalian infection. The use of cocktails consisting of multiple recombinant $\mathrm{OspC}$ proteins has not proven effective, possibly due to misdirection of immune responses to immunodominant epitopes that do not elicit protective antibody responses (Earnhart and Marconi, 2008; Marconi and Earnhart, 2010). Chimeric recombinant proteins offer a conceptually promising approach for the development of

\footnotetext{
${ }^{1}$ See: http://www.cdc.gov.
} 
broadly protective vaccines. An octavalent recombinant chimeric protein that consists of linearepitopes derived from the loop 5 and a helix 5 domains of OspC elicited bactericidal antibody against strains producing $\mathrm{OspC}$ type proteins represented in the vaccine construct (Earnhart et al., 2007a; Earnhart and Marconi, 2007b and c). This finding indicates that a chimeric approach to Lyme disease vaccine development is possible.

To facilitate the rational design of a cost effective, broadly protective, OspC based vaccine intended for use in dogs, it is essential to identify the $\operatorname{sp} C$ genotypes most commonly associated with strains that successfully infect dogs. Towards this goal, field caught Ixodes scapularis ticks collected from Rhode Island were fed on laboratory raised dogs, tissue biopsies were collected and the $\operatorname{spC}$ genotype of strains present in tissue and tissue-derived cultures were determined. The results demonstrate that unique $\operatorname{ssp} C$ types rarely recovered from human Lyme disease patients predominate in canine infections. This observation indicates that a chimeric OspC based Lyme disease vaccine intended for use in dogs must consist of different component epitopes than a vaccine intended for use in humans. The data have significant implications for the design of a broadly protective OspC based vaccine for use in dogs.

\section{Methods and materials}

\section{Tick collection and analysis}

Adult I. scapularis ticks were collected in southern Rhode Island in the spring of 2008 by flagging. The percentage of ticks infected with B. burgdorferi was determined by direct fluorescent microscopy using standard methods and labeled anti-B. burgdorferi antibody (Nicholson et al., 1996).

\section{Infestation of dogs with field caught ticks}

All procedures were conducted in compliance with regulations of the Animal Welfare Act. The study protocol (\#KZ-1201e-2005-08pxm) was reviewed and approved (16 May 2008) by Pfizer's Animal Care and Use Committee prior to the start of the study. Fifteen purposebred beagles of both sexes ( 7 males, 8 females; 9 to 10 weeks of age; Marshall Bioresources) were assigned identification numbers and divided into four groups, designated T01 $(n=4)$, T02 $(n=4)$, T03 $(n=4)$ and T04 $(n=3)$. The dogs were fitted with Elizabethan collars and housed in one-over 115 one condominium style cages. The dogs were acclimatized to the collars by having them wear the collars for increasing amounts of time over several days.

Thirteen days prior to tick infestation, serum was collected from each dog. Dogs in groups T01, T02, T03 and T04 were infested with $0,25,50$ or 75 adult $I$. scapularis ticks, respectively, using secured infestation chambers placed on each side of the mid-thorax. The chambers were adhered using Elastikon (Johnson and Johnson). To ensure that the dogs did not interfere with the chambers, each was fitted with a lightweight jacket. Ticks were fed to repletion, removed and serum samples $(5 \mathrm{~mL})$ collected on days $-13,21,35,49,63,77$ and 92. Skin biopsies $(2 \mathrm{~mm})$ were collected at $49 \mathrm{dpi}$. Seroconversion was assessed with the 4DX SNAP test (IDEXX) and C6 titers determined on a fee for service basis by IDEXX using a semi-quantitative ELISA (Lyme Quant C6 Test).

To cultivate spirochetes from infected dogs, approximately half of each $2 \mathrm{~mm}$ skin biopsy was placed in $6 \mathrm{~mL}$ BSK-H media (Sigma) supplemented with 6\% rabbit serum (Sigma) and Borrelia antibiotic cocktail (phosphomycin, amphotericin B and rifampicin; Sigma) and the cultures maintained at $37^{\circ} \mathrm{C}$ under $5 \% \mathrm{CO}_{2}$. Clonal populations were obtained from the cultures by sub surface plating (Sung et al., 2001). Colonies were excised from the plates 
and placed in BSK-Hmedia for cultivation. The uncloned isolates recovered from the tissue biopsies were designated as DRI indicating that they originated from dogs (D) that were infected using ticks collected in Rhode Island (RI). DRI is followed by a portion of the identifier number that was assigned to each dog. Lower case letters that follow the number indicate a specific clone derived from the uncloned isolate by subsurfacing plating as detailed above.

\section{DNA extraction and PCR}

DNA was extracted from the remaining half of each skin biopsy using the Qiagen DNeasy Kit and from cultures of B. burgdorferi clonal populations as described previously (McDowell et al., 2001). The ospC and flaB genes were amplified by PCR using DNA (100 ng) extracted from tissues and from the supernatant of boiled B. burgdorferi cell lysates. PCR was performed using standard conditions, GoTaq polymerase (Promega) and the following primers; ospC-F1 5'-

GACGACGACAAGATTGAATACATTAAGTGCAATATTAATGAC-3' and $o s p C$-R1 5'GAGGAGAAGCCCGGTTTACAAATTAATCTTATAATATTGATCTT AATTAAGG-3' The primers used to amplify flaB have been described previously (Zhang and Marconi, 2005). The amplicons were assessed by agarose gel electrophoresis and ethidium bromide staining.

The PCR products obtained from amplification of DNA extracted from tissues were excised from the gels using the Qiagen Gel Extraction Kit, cloned into the pET46EK/LIC vector (Novagen) and the plasmids were propagated in Escherichia coli NovaBlue cells (Novagen). The resulting $E$. coli colonies were screened for $o s p C$ by PCR using cell lysates obtained by boiling E. coli colonies in water. Portions of the ospC PCR positive colonies were transferred into Luria-Bertani broth media $(2 \mathrm{~mL})$ and grown overnight. Cells were harvested by centrifugation and plasmids were extracted using the Qiagen MiniPrep kit. PCR amplicons obtained by amplification of $o s p C$ from B. burgdorferi colonies were directly sequenced after purification and were not cloned into a plasmid.

\section{Phylogenetic analysis}

DNA sequencing was performed by Eurofins MWG Operon. Phylogenetic analyses were conducted as described previously (Earnhart and Marconi, 2007c). Neighbor joining trees were generated using ClustalX 2.0.10 software in the multiple alignment mode with the default settings and a Gonnet matrix, and were visualized using N-J Plot version 2.2.

Previously determined sequences of known ospC type were included in the analysis in order to assign type designations to the sequences determined in this study.

\section{Results}

\section{Analysis of the prevalence of B. burgdorferi in ticks collected from Rhode Island}

Using a standardized direct fluorescent microscopy method (Nicholson et al., 1996), 52\% of the I. scapularis ticks field-collected in southern Rhode Island during the Spring of 2008 were infected with B. burgdorferi. Tick infection rates (TIRs) for Spring-collected adult female I. scapularis collected at the same set of sites in southern Rhode Island ranged from 50-70\% from 2004-2009 (average 55.4\%). Relatively high TIRs in nymphal ( 25\%) and adult (55\%) I. scapularis and abundance levels of both developmental stages are consistent with the high incidence of human Lyme disease cases in Rhode Island ( 17 per 100,000 
people statewide from 2006 to $2010^{2}$, with $\sim 50$ times more human cases per 100,000 people in southern Rhode Island towns (T. Mather; unpublished results).

\section{Infection of dogs with B. burgdorferi through tick infestation}

Field collected ticks were fed on dogs that had been confirmed to be seronegative at the start of the study. Since the infection rate in the field collected ticks was $52 \%$ and since typically not all ticks placed on an animal will feed, dogs in groups T02, T03 and T04 were infested with 25, 50 or 75 ticks. Tick attachment rates ranged from 3\% for dog 730173 (group T04) to $100 \%$ for $\operatorname{dog} 729485$ (group T02). The average tick attachment rate for animals in groups T02, T03 and T04 was 46\%. Serum samples were collected -13, 21, 35, 49, 63, 77 and $92 \mathrm{dpi}$ and evaluated for antibodies against B. burgdorferi and Anaplasma phagocytophilum/A. platys antigens using the +SNAP 4DX test (Table 1). Ten of eleven tick-infested dogs were positive for B. burgdorferi and all of the tick 188 infested dogs were positive for A. phagocytophilum/A. platys. Anaplasma infection was not verified using other SNAP independent methods. The $\operatorname{dog}$ in group T04 that was antibody negative for $B$. burgdorferi was removed from the study and was not analyzed further, bringing the total number of dogs in the study to 14 . Dogs in group T01 (not tick infested, negative controls dogs) remained negative by the SNAP test for B. burgdorferi and A. phagocytophilum/A. platys over the course of the study. Antibody titers against the VlsE derived C6 peptide were determined using the Lyme C6 Quantitative Antibody test. The minimum and maximum titers for each group at each time point and the geometric means are listed in Table 1. Most dogs in groups T02, T03 and T04 displayed significant antibody titers starting at day 35 post-infestation. The number of ticks that were fed on each dog did not appear to influence antibody titer. The presence of spirochetes in tissue of dogs that were seropositive was demonstrated using PCR. All seropositive dogs yielded ospC and flaB amplicons of the predicted size, whereas all seronegative dogs were PCR negative for both genes (data not shown). Infection status was further evaluated by cultivation of spirochetes from tissue biopsies. All tick infested dogs (except the single dog that was removed from group T04, as discussed above) yielded positive cultures while dogs in group T01 were culture negative.

\section{Analysis of ospC diversity in strains found in culture positive dog tissues}

To determine the $\operatorname{sp} C$ genotype of strains in the skin of $\operatorname{dogs}$ exposed to ticks, $o s p C$ was PCR amplified from DNA extracted from skin biopsies. The resulting amplicons were cloned and sequenced. Five or more E. coli colonies for each cloned amplicon were selected for $\operatorname{ss} C$ sequence determination. The resulting sequences were aligned and a dendrogram was constructed (Fig. 1). Six of the ten dogs were infected with multiple strains as inferred from the amplification of multiple $o s p C$ types from the DNA extracted from the skin biopsies (Table 2). ospC types A, B, F, I and $\mathrm{N}$ were identified, with types $\mathrm{F}$ and $\mathrm{N}$ being the most prevalent (5/10 and 7/10 dogs, respectively).

It is possible that there could have been strains present in the infected tissues that were not efficiently amplified by PCR. To further define the range of $\operatorname{ss} C$ genotypes present in the infected dogs, uncloned B. burgdorferi cultures derived from the skin biopsies were plated and clonal populations obtained. ospC was then amplified from individual colonies and the sequence of the amplicons determined (a dendrogram depicting the sequencing results is presented in Fig. 2). ospC types that were not detected by direct PCR of tissue biopsies were identified in 3/6 dogs. Two of the identified $o s p C$ types, both of which originated from the same dog, had not been previously described in the literature. These phyletic types were designated DRI85a and DRI85e. Other ospC types identified by this approach included

${ }^{2}$ See: http://www.cdc.gov. 
types E, F, H, I, N, U and T (Table 1). Collectively, a total of 11 different $o s p C$ types were detected in dogs infected with wild caught ticks from Rhode Island.

\section{Discussion}

It has been postulated that the $\operatorname{sp} C$ genotype of $B$. burgdorferi may influence strain host range and, consistent with this hypothesis, only a limited subset of OspC types (A, B, C, D, $\mathrm{I}$, and $\mathrm{K}$ ) are most commonly associated with invasive disease in humans (Seinost et al., 1999a; Buckles et al., 2006; Earnhart et al., 2005). The diversity of $o s p C$ types associated with infection in dogs had not been assessed previously. This is a critical step in efforts to develop a broadly protective OspC based Lyme disease subunit vaccine for use in dogs and potentially other companion animals. In this study we determined the $\operatorname{ss} C$ genotype of Lyme disease spirochete strains recovered from dog tissue 49 dpi. Field collected $I$. scapularis ticks from Rhode Island were fed on laboratory dogs and the $o s p C$ genotype of strains present in skin were determined at $49 \mathrm{dpi}$.

A total of 11 different $\operatorname{ssp} C$ types were identified, with $\operatorname{ssp} C$ type $\mathrm{F}$ being the most frequently detected (50\% of infected dogs). While ospC type $\mathrm{F}$ is among the more common ospC phyletic types found in ticks in Medocino, California (Girard et al., 2009), to date there is only a single database report of an $o s p C$ type $\mathrm{F}$ strain that originated from humans. Types B, N and U, which occur at low frequency in humans (Seinost et al., 1999a and b; Earnhart and Marconi, 2007c; Brisson et al., 2011), were also detected in the dogs. Two ospC sequences were determined that differed in sequence by more than $5 \%$ from previously delineated $o s p C$ types. A 5\% difference in sequence is considered to be sufficient to warrant the designation of a new $o s p C$ type (Earnhart and Marconi, 2007c). These variant $o s p C$ sequences originated from clones derived from the DRI85 isolate and were assigned the phyletic type designations DRI85a and DRI85e.

It is noteworthy that the dominant $o s p C$ types identified in the cultures derived from canine tissues differed from those most readily detected by direct PCR of the tissue. For example, whiletype $\mathrm{F}$ and type $\mathrm{N}$ ospC were directly amplified from most tissue samples, these $o s p C$ types were only detected in a single tissue derived culture. Strains producing OspC types $\mathrm{F}$ and $\mathrm{N}$ have growth rates similar to that of strains producing other OspC types, so this observation is not likely to be due to the inability of type $\mathrm{F}$ strains to adapt to in vitro cultivation conditions. The results presented here are consistent with a previous report that demonstrated greater $B$. burgdorferi diversity directly in human tissue samples relative to cultures derived from the same tissue samples (Liveris et al., 1999). Collectively, these analyses demonstrate that multiple approaches are required to accurately assess the genetic diversity of infecting strains.

The diversity observed in this study is consistent with earlier studies that demonstrated the maintenance of several ospC phyletic types within a local B. burgdorferi population (Wang et al., 1999; Qiu et al., 2002; Alghaferi et al., 2005; Earnhart et al., 2005; Anderson and Norris, 2006). In that the ticks used in this study were collected from a single geographic region, it is possible that strains producing other OspC types that are not well represented in Rhode Island are also competent to infect dogs. Future analyses, using ticks collected from other geographic regions will assess this possibility. In spite of this caveat, this study is the first to demonstrate that $o s p C$ types not previously associated with human infection can infect dogs. The data suggest that an OspC based vaccine intended for use in dogs needs to be designed to include different epitopes than those being used in the development of a human OspC-derived chimeric vaccine. 


\section{Conclusions}

The $\operatorname{ssp} C$ genotypes of $B$. burgdorferi strains that successfully established infection in dogs after tick infestation were determined. Some unique $\operatorname{sp} P$ phyletic types that had not been previously described were detected. Overall the $\operatorname{ss} C$ genotypes most commonly detected in dogs differed from those that have been demonstrated in humans. These findings have significant implications for the design of OspC-based canine Lyme disease vaccines and diagnostic assays.

\section{Acknowledgments}

We thank our colleagues at Virginia Commonwealth University and Zoetis for their input and support. This work was supported in part through a research agreement with Zoetis (previously Pfizer Animal Health) and by a grant from the National Institutes of Health (5R01AI067746).

\section{References}

Alghaferi MY, Anderson JM, Park J, Auwaerter PG, Aucott JN, Norris DE, Dumler JS. Borrelia burgdorferi ospC heterogeneity among human and murine isolates from a defined region of northern Maryland and southern Pennsylvania: Lack of correlation with invasive and noninvasive genotypes. Journal of Clinical Microbiology. 2005; 43:1879-1884. [PubMed: 15815012]

Anderson JM, Norris DE. Genetic diversity of Borrelia burgdorferi sensu stricto in Peromyscus leucopus the primary reservoir of Lyme disease in a region of endemicity in Southern Maryland. Applied and Environmental Microbiology. 2006; 72:5331-5341. [PubMed: 16885284]

Benach JL, Bosler EM, Hanrahan JP, Coleman JL, Habicht GS, Bast TF, Cameron DJ, Ziegler JL, Barbour AG, Burgdorfer W, et al. Spirochetes isolated from the blood of two patients with Lyme disease. New England Journal of Medicine. 1983; 308:740-742. [PubMed: 6828119]

Baranton G, Postic D, Saint Girons I, Boerlin P, Piffaretti J-C, Assous M, Grimont PAD. Delineation of Borrelia burgdorferi sensu stricto, Borrelia garinii sp. nov., group VS461 associated with Lyme borreliosis. International Journal of Systematic Bacteriology. 1992; 42:378-383. [PubMed: 1380285]

Bowman D, Little SE, Lorentzen L, Shields J, Sullivan MP, Carlin EP. Prevalence and geographic distribution of Dirofilaria immitis, Borrelia burgdorferi, Ehrlichia canis and in dogs in the United States: Results of a national clinic-based serologic survey. Veterinary Parasitology. 2009; 160:138148. [PubMed: 19150176]

Brisson D, Baxamusa N, Schwartz I, Wormser GP. Biodiversity of Borrelia burgdorferi strains in tissues of Lyme disease patients. PLoS One. 2011; 6:e22926. [PubMed: 21829670]

Brisson D, Dykhuizen DE. ospC diversity in Borrelia burgdorferi: Different hosts are different niches. Genetics. 2004; 168:713-722. [PubMed: 15514047]

Buckles EL, Earnhart CG, Marconi RT. Analysis of antibody response in humans to the type A OspC loop 5 domain and assessment of the potential utility of the loop 5 epitope in Lyme disease vaccine development. Clinical and Vaccine Immunology. 2006; 13:1162-1165. [PubMed: 17028218]

Burgdorfer W, Barbour AG, Hayes SF, Benach JL, Grunwaldt E, Davis JP. Lyme disease - a tickborne spirochetosis? Science. 1982; 216:1317-1319. [PubMed: 7043737]

Earnhart, C.; Marconi, RT. Lyme disease. In: Barrett, AD.; Stanberry, LR., editors. Vaccines for Biodefense and Emerging and Neglected Diseases. London, UK: Elsevier; 2008. p. 1478

Earnhart CG, Buckles EL, Dumler JS, Marconi RT. Demonstration of OspC type diversity in invasive human Lyme disease isolates and identification of previously uncharacterized epitopes that define the specificity of the $O s p C$ murine antibody response. Infection and Immunity. 2005; 73:78697877. [PubMed: 16299277]

Earnhart CG, Buckles EL, Marconi RT. Development of an $O s p C$-based tetravalent, recombinant, chimeric vaccinogen that elicits bactericidal antibody against diverse Lyme disease spirochete strains. Vaccine. 2007; 25:466-480. [PubMed: 16996663]

Earnhart CG, Leblanc DV, Alix KE, Desrosiers DC, Radolf JD, Marconi RT. Identification of residues within ligand-binding domain 1 (LBD1) of the Borrelia burgdorferi OspC protein required for 
function in the mammalian environment. Molecular Microbiology. 2010; 76:393-408. [PubMed: 20199597]

Earnhart CG, Marconi RT. Construction and analysis of variants of a polyvalent Lyme disease vaccine: Approaches for improving the immune response to chimeric vaccinogens. Vaccine. 2007a; 25:3419-3427. [PubMed: 17239505]

Earnhart CG, Marconi RT. An octavalent lyme disease vaccine induces antibodies that recognize all incorporated $O s p C$ type-specific sequences. Human Vaccine. 2007b; 3:281-289.

Earnhart CG, Marconi RT. OspC phylogenetic analyses support the feasibility of a broadly protective polyvalent chimeric Lyme disease vaccine. Clinical and Vaccine Immunology. 2007c; 14:628634. [PubMed: 17360854]

Fuchs R, Jauris S, Lottspeich F, Preac-Mursic V, Wilske B, Soutschek E. Molecular analysis and expression of a Borrelia burgdorferi gene encoding a $22 \mathrm{kDa}$ protein (pC) in Escherichia coli. Molecular Microbiology. 1992; 6:503-509. [PubMed: 1560779]

Girard YA, Travinsky B, Schotthoefer A, Fedorova N, Eisen RJ, Eisen L, Barbour AG, Lane RS. Population Structure of the Lyme borreliosis spirochete Borrelia burgdorferi in the western blacklegged tick (Ixodes pacificus) in northern California. Applied Environmental. Microbiology. 2009; 75:7243-7252.

Hovius JW, Schuijt TJ, de Groot KA, Roelofs JJ, Oei GA, Marquart JA, de Beer R, van 't Veer C, van der Poll T, Ramamoorthi N, et al. Preferential protection of Borrelia burgdorferi sensu stricto by a Salp15 homologue in Ixodes ricinus saliva. Journal of Infectious Diseases. 2008; 198:1189-1197. [PubMed: 18752445]

Krupka I, Straubinger RK. Lyme borreliosis in dogs and cats: Background, diagnosis, treatment and prevention of infections with Borrelia burgdorferi sensu stricto. Veterinary Clinics of North America: Small Animal Practice. 2010; 40:1103-1119.

LaFleur RL, Callister SM, Dant JC, Jobe DA, Lovrich SD, Warner TF, Wasmoen TL, Schell RF. Oneyear duration of immunity induced by vaccination with a canine Lyme disease bacterin. Clinical and Vaccine Immunology. 2010; 17:870-874. [PubMed: 20237200]

Lagal V, Portnoi D, Faure G, Postic D, Baranton G. Borrelia burgdorferi sensu stricto invasiveness is correlated with OspC-plasminogen affinity. Microbes and Infection. 2006; 8:645-652. [PubMed: 16513394]

Little SE, Heise SR, Blagburn BL, Callister SM, Mead PS. Lyme borreliosis in dogs and humans in the USA. Trends in Parasitology. 2010; 26:213-218. [PubMed: 20207198]

Littman MP, Goldstein RE, Labato MA, Lappin MR, Moore GE. ACVIM small animal consensus statement on Lyme disease in dogs: Diagnosis, treatment, and prevention. Journal of Veterinary Internal Medicine. 2006; 20:422-434. [PubMed: 16594606]

Liveris D, Varde S, Iyer R, Koenig S, Bittker S, Cooper D, McKenna D, Nowakowski J, Nadelman $\mathrm{RB}$, Wormser GP, et al. Genetic diversity of Borrelia burgdorferi in Lyme disease patients as determined by culture versus direct PCR with clinical specimens. Journal of Clinical Microbiology. 1999; 37:565-569. [PubMed: 9986813]

Marconi RT, Garon CF. Identification of a third genomic group of Borrelia burgdorferi through signature nucleotide analysis and 16S rRNA sequence determination. Journal of General Microbiology. 1992; 138:533-536. [PubMed: 1593264]

Marconi, RT.; Earnhart, C. Lyme disease vaccines. In: Samuels, DS.; Radolf, J., editors. Borrelia: Molecular biology, host interaction and pathogenesis. Norfolk, UK: Caister Academic Press; 2010. p. 467-486.

Marconi RT, Samuels DS, Garon CF. Transcriptional analyses and mapping of the ospC gene in Lyme disease spirochetes. Journal of Bacteriology. 1993b; 175:926-932. [PubMed: 7679385]

Marconi RT, Samuels DS, Schwan TG, Garon CF. Identification of a protein in several Borrelia species which is related to OspC of the Lyme disease spirochetes. Journal of Clinical Microbiology. 1993b; 31:2577-2583. [PubMed: 8253952]

McDowell JV, Sung SY, Labandeira-Rey M, Skare JT, Marconi RT. Analysis of mechanisms associated with loss of infectivity of clonal populations of Borrelia burgdorferi B31MI. Infection and Immunity. 2001; 69:3670-3677. [PubMed: 11349029] 
Nicholson MC, Mather TN, Donnelly EF. Lyme disease in Rhode Island: Three years of surveillance. Medicine and Health Rhode Island. 1996; 79:311-313.

Onder O, Humphrey PT, McOmber B, Korobova F, Francella N, Greenbaum DC, Brisson D. OspC is potent plasminogen receptor on surface of Borrelia burgdorferi. Journal of Biological Chemistry. 2012; 287:16860-16868. [PubMed: 22433849]

Qiu WG, Dykhuizen DE, Acosta MS, Luft BJ. Geographic uniformity of the Lyme disease spirochete (Borrelia burgdorferi) and its shared history with tick vector (Ixodes scapularis) in the Northeastern United States. Genetics. 2002; 160:833-849. [PubMed: 11901105]

Sadziene A, Wilske B, Ferdows MS, Barbour AG. The cryptic ospC gene of Borrelia burgdorferi B31 is located on a circular plasmid. Infection and Immunity. 1993; 61:2192-2195. [PubMed: 8478109]

35. Seinost G, Dykhuizen DE, Dattwyler RJ, Golde WT, Dunn JJ, Wang IN, Wormser GP, Schriefer ME, Luft BJ. Four clones of Borrelia burgdorferi sensu stricto cause invasive infection in humans. Infection and Immunity. 1999a; 67:3518-3524. [PubMed: 10377134]

36. Seinost G, Golde WT, Berger BW, Dunn JJ, Qiu D, Dunkin DS, Dykhuizen DE, Luft BJ, Dattwyler RJ. Infection with multiple strains of Borrelia burgdorferi sensu stricto in patients with Lyme disease. Archives of Dermatology. 1999a; 135:1329-1333. [PubMed: 10566830]

Sung SY, McDowell JV, Marconi RT. Evidence for the contribution of point mutations to vlsE variation and for apparent constraints on the net accumulation of sequence changes in vlsE during infection with Lyme disease spirochetes. Journal of Bacteriology. 2001; 183:5855-5861. [PubMed: 11566983]

Theisen M, Borre M, Mathiesen MJ, Mikkelsen B, Lebech AM, Hansen K. Evolution of the Borrelia burgdorferi outer surface protein OspC. Journal of Bacteriology. 1995; 177:3036-3044. [PubMed: 7768799]

Theisen M, Frederiksen B, Lebech AM, Vuust J, Hansen K. Polymorphism in ospC gene of Borrelia burgdorferiand immunoreactivity of OspC protein: Implications for taxonomy and for use of OspC protein as a diagnostic antigen. Journal of Clinical Microbiology. 1993; 31:2570-2576. [PubMed: 8253951]

Wang IN, Dykhuizen DE, Qiu W, Dunn JJ, Bosler EM, Luft BJ. Genetic diversity of $\operatorname{ssp} C$ in a local population of Borrelia burgdorferi sensu stricto. Genetics. 1999; 151:15-30. [PubMed: 9872945]

Wilske B, Busch U, Fingerle V, Jauris-Heipke S, Preac Mursic V, Rossler D, Will G. Immunological and molecular variability of OspA and OspC. Implications for Borrelia vaccine development. Infection. 1996; 24:208-212. [PubMed: 8740124]

Wilske B, Preac-Mursic V, Jauris S, Hofmann A, Pradel I, Soutschek E, Schwab E, Will G, Wanner G. Immunological and molecular polymorphisms of OspC, an immunodominant major outer surface protein of Borrelia burgdorferi. Infection and Immunity. 1993; 61:2182-2191. [PubMed: 8478108]

Zhang H, Marconi RT. Demonstration of cotranscription and 1-methyl-3-nitroso- nitroguanidine induction of a 30-gene operon of Borrelia burgdorferi: Evidence that the 32-kilobase circular plasmids are prophages. Journal of Bacteriology. 2005; 187:7985-7995. [PubMed: 16291672] 


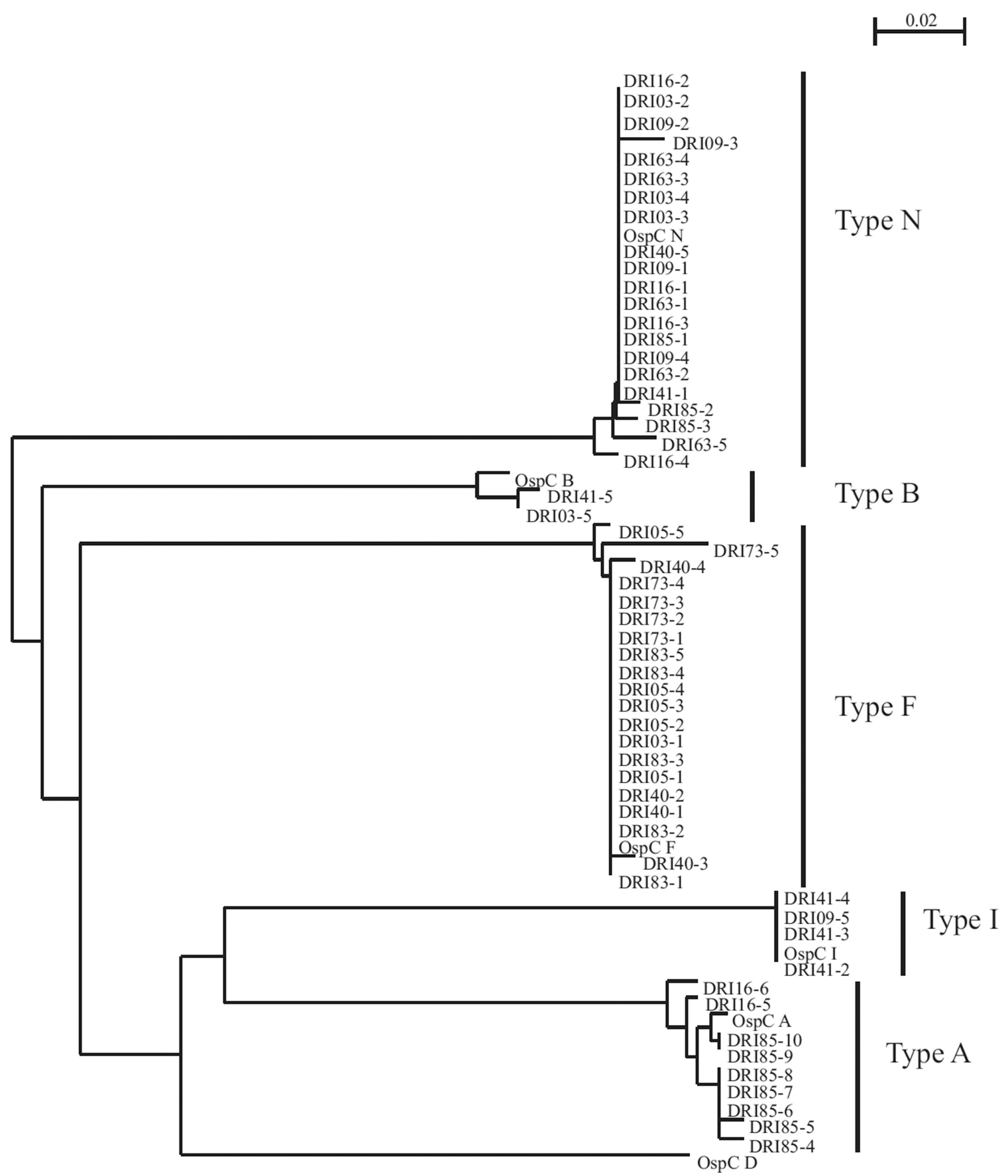

Fig 1.

Phylogenetic analysis of OspC sequences amplified directly from skin biopsy samples collected from dogs after infestation with ticks. ospC was PCR amplified directly from skin biopsies and the amplicons were cloned into E. coli. Recombinant plasmids were isolated from several independent colonies for each cloning reaction and the sequence of the inserts was determined. The nomenclature used for the determined sequences is as described in the text. Note that individual sequences cloned from a single PCR reaction are differentiated by a hyphenated number. The translated sequences were aligned and a dendrogram constructed. $o s p C$ type identity was determined by comparative analysis with previously determined 
$o s p C$ sequences of known phyletic type. ospC type identity is indicated to the right by bracketing. The scale bar indicates substitutions per sequence position. 


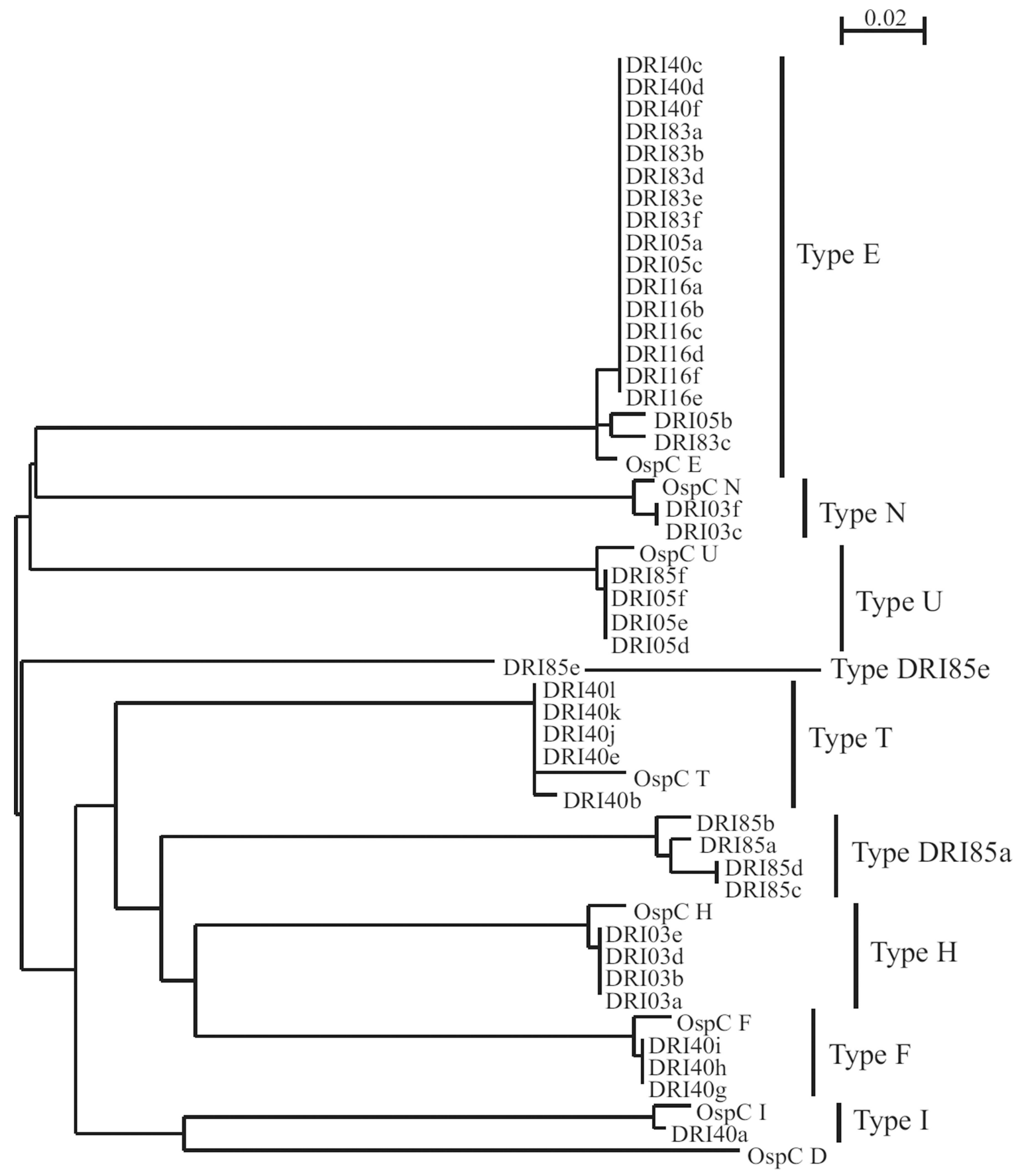

Fig 2.

Phylogenetic analysis of OspC sequences derived from clonal populations of Borrelia burgdorferi cultivated from biopsies from dogs. Biopsy samples were placed in media and spirochetes cultivated. The cultures were sub-surface plated, individual colonies were picked, $\operatorname{sp} C$ was amplified and the $\operatorname{sp} C$ sequences determined. The scale bar indicates substitutions per sequence position. 


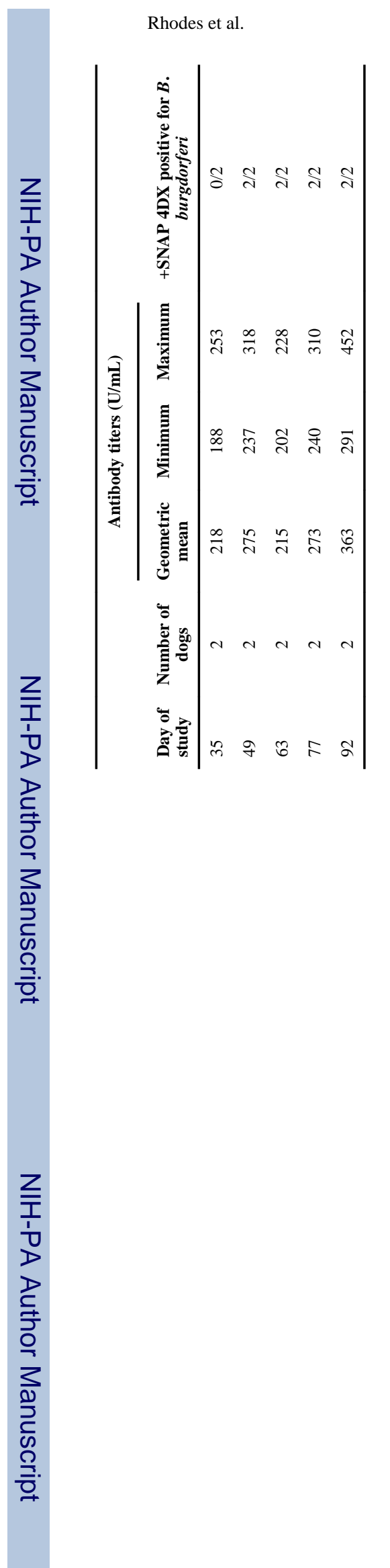

Vet J. Author manuscript; available in PMC 2014 November 01. 
Table 2

OspC phyletic types identified in tick infested dogs

\begin{tabular}{|c|c|c|c|c|}
\hline Group & $\begin{array}{l}\text { Individual animal } \\
\text { identifier number }\end{array}$ & $\begin{array}{l}\text { Designation for tissue } \\
\text { derived isolate }\end{array}$ & $\begin{array}{l}\text { OspC types PCR amplified } \\
\text { directly from tissue }\end{array}$ & $\begin{array}{l}\text { OspC types PCR amplified } \\
\text { from biopsy derived cultures }\end{array}$ \\
\hline \multirow[t]{2}{*}{$\mathrm{T} 01$} & 729451,729566 & None recovered & Not applicable & Not applicable \\
\hline & 729680,729698 & & & \\
\hline \multirow[t]{4}{*}{ T02 } & 729485 & DRI85 & $\mathrm{A}, \mathrm{N}$ & U, DRI85a, DRI85e \\
\hline & 729663 & DRI63 & $\mathrm{N}$ & Not determined \\
\hline & 730416 & DRI16 & $\mathrm{A}, \mathrm{N}$ & $\mathrm{E}$ \\
\hline & 730203 & DRI03 & $\mathrm{B}, \mathrm{F}, \mathrm{N}$ & $\mathrm{H}, \mathrm{N}$ \\
\hline \multirow[t]{4}{*}{ T03 } & 730009 & DRI09 & $\mathrm{I}, \mathrm{N}$ & $\mathrm{Na}$ \\
\hline & 730505 & DRI05 & $\mathrm{F}$ & $\mathrm{E}, \mathrm{U}$ \\
\hline & 730441 & DRI41 & $\mathrm{B}, \mathrm{I}, \mathrm{N}$ & Not determined \\
\hline & 730483 & DRI83 & $\mathrm{F}$ & $\mathrm{E}$ \\
\hline \multirow[t]{2}{*}{$\mathrm{T}_{0} 4^{a}$} & 729540 & DRI40 & $\mathrm{F}, \mathrm{N}$ & $\mathrm{E}, \mathrm{I}, \mathrm{F}, \mathrm{T}$ \\
\hline & 730173 & DRI73 & $\mathrm{F}$ & Not determined \\
\hline
\end{tabular}

